\title{
LOW-COST ELECTROPLATED VERTICAL COMB-DRIVE
}

\author{
Zhihong Li and Norman Tien \\ Berkeley Sensor and Actuator Center, Department of Electrical and Computer Engineering \\ University of California, Davis, CA 95616
}

\begin{abstract}
A low-cost, vertical comb-drive actuator has been developed employing a thick photoresist and electroplating process. The thickness of the metallic structures can be varied from a few microns to tens of microns. Utilizing this technique scanning mirrors with a reflecting area of $500 \mu \mathrm{m} \times 500 \mu \mathrm{m}$ and scanning angle up to \pm 10 optical degrees at resonant mode have been designed, fabricated and tested.
\end{abstract}

\section{INTRODUCTION}

Vertical comb-drive actuators (VCA's) have received significant research attention as they can directly provide torque and large out-of-plane motion, which is very important for optical applications such as scanning mirrors for raster scanning displays and optical communications [1-5]. VCA's have also been reported to realize other devices such as tunable capacitors with a high tuning ratio [6].

Previously reported methods of fabricating VCA's utilized DRIE, backside through-wafer etching, wafer bonding or doublesided alignment on expensive SOI wafers [1-5]. Such processes would result in high fabrication costs for products containing VCA's. In this work, we utilize the process of electroplating with a photoresist mold to fabricate VCA's, which is very inexpensive and can be applied to any substrate [7, 8]. Only two masks, neither requiring critical alignment, are employed. In addition, the thickness of the structures, as well as the overlap between upper comb fingers and lower comb fingers, can easily be varied from a few microns to tens of microns by using different photoresists and process parameters. If SU-8, an ultra-thick and high aspect ratio photoresist $[9,10]$, is employed, structures may be realized with thickness greater than $100 \mu \mathrm{m}$. The metallic structures are advantageous for RF applications due to the low resistivity.

\section{DEVICE DESIGN}

Fig.1 (a) and Fig.1 (b) show micrographs of torsional scanning mirrors with different configurations (called Type A and Type B herein), which were designed and fabricated to validate the technique discussed. The reflecting area of the mirrors was $500 \mu \mathrm{m} \times 500 \mu \mathrm{m}$ and the length of comb fingers was $100 \mu \mathrm{m}$ or $200 \mu \mathrm{m}$. The designed width and spacing of comb fingers were $(5 \mu \mathrm{m}, 5 \mu \mathrm{m}),(4 \mu \mathrm{m}, 6 \mu \mathrm{m})$ or $(6 \mu \mathrm{m}, 6 \mu \mathrm{m})$ to find an optimized design. In the Type A mirror, the width and length of the torsional beams were $4 \mu \mathrm{m}$ and $100 \mu \mathrm{m}$ respectively, while they were $5 \mu \mathrm{m}$ and $300 \mu \mathrm{m}$ in the Type B mirror.

Fig. 2 shows a 3-dimesional schematic drawing of the scanning Type A mirror, in which the substrate is recessed by $\mathrm{KOH}$ etching to increase the maximum achievable tilt angle and to decrease the damping coefficient due to the squeezing film effect.
Under electrostatic actuation, the torque, $T$, resulting from the change of capacitance is derived from $[4,5]$

$T=\frac{\partial C}{\partial \theta} \frac{V^{2}}{2}$

where $V$ is the applied voltage, $C$ is the capacitance between fixed comb fingers and moving comb fingers, and $\theta$ is the angular displacement. Ignoring the fringing filed, the capacitance, $\mathrm{C}$, is a function of $\theta[4]$ :

$C=2 \frac{N \varepsilon_{0} A(\theta)}{g}$

where $N$ is the number of pairs of the comb fingers, $\varepsilon_{o}$ is the permittivity of free space, $A(\theta)$ is the overlap area as a function of $\theta$, and $g$ is the spacing between comb fingers. Under DC actuation, $\theta$ reaches the maximum value at maximum capacitance, i.e., the maximum overlap area, $A(\theta)$. The tilt angle under $\mathrm{AC}$ actuation can be much larger than DC actuation if the mechanical quality factor $(Q)$ is high enough, because the comb fingers could go beyond the balanced position due to overshooting. The maximum tilt angle is dependent on the geometry of the device, the quality factor, and the waveform of the AC actuations. This will not be discussed in detail in this paper.

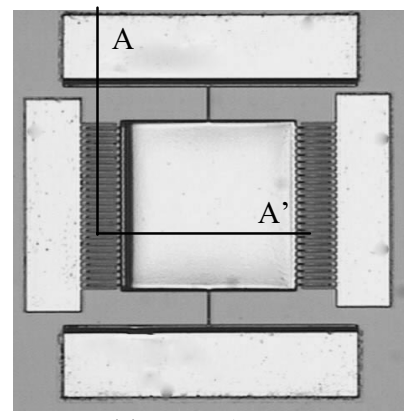

(a) Type A

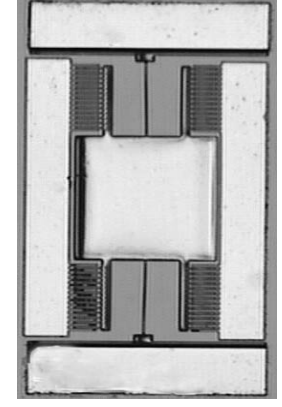

(b) Type B
Figure 1. Micrographs of the fabricated mirrors with different layouts.

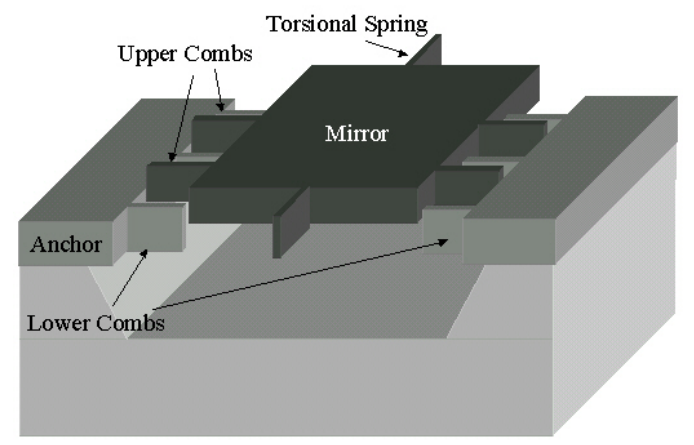

Figure 2. 3-dimensional schematic drawing of the scanning mirror. 


\section{PROCESS}

A typical process flow along cross section A-A' (indicate cross section line) in Fig.1 (a) is shown in Fig.3. In the process, a PECVD oxide layer was employed as a plating-block mask for the lower comb fingers and anchors, and a $\mathrm{Cu}$ layer served as both a sacrificial and lifting layer for the mirrors and upper comb fingers. Therefore, self-aligned asymmetric upper comb fingers and lower comb fingers were achieved with a single step Ni plating. (a) A layer of $\mathrm{Ni} / \mathrm{Cr}(1000 \AA / 100 \AA)$ was evaporated as a seed layer on a 4' silicon wafer with $1.1 \mu \mathrm{m}$ thermal oxide. (b) A $0.3 \mu \mathrm{m}$ PECVD oxide was deposited and patterned by RIE to form a plating-block for the lower comb fingers and anchors. (c) $20 \mu \mathrm{m}$ of AZ4620 photoresist was spun (double coating) and patterned with a Karl Suss MA4 contact aligner to form an electroplating mold. The designed width and spacing of comb fingers was $5 \mu \mathrm{m}$, and the aspect ratio was 4:1. (d) An $8 \mu \mathrm{m} \mathrm{Cu}$ layer was electroplated onto the mirror and upper comb fingers, while the anchors and lower comb fingers were not plated because they were covered with the PECVD oxide layer. (e) A $9 \mu \mathrm{m}$ Ni layer was electroplated on both the $\mathrm{Cu}$ layer and the $\mathrm{Ni}$ seed layer after a BOE strip of the oxide. Therefore, the thickness of both upper and lower comb fingers was $9 \mu \mathrm{m}$ with a $1 \mu \mathrm{m}$ overlap. The Ni was plated in Technics Nickel $S$ sulfamate solution (Technics Inc.) at $40^{\circ} \mathrm{C}$ under pulsed direct current with a current density of $60 \mathrm{~mA} / \mathrm{cm}^{2}$, a frequency of $1 \mathrm{kHz}$ and a duty cycle of $50 \%$. A $15 \mathrm{~mL} / \mathrm{Ga}$ stress reducer/brightener was added to the solution to reduce the residual stress and to increase surface reflectivity. (f) The $\mathrm{Cu}$ layer was etched in $\mathrm{C}_{2} \mathrm{H}_{4} \mathrm{O}_{2}: \mathrm{H}_{2} \mathrm{O}_{2}: \mathrm{H}_{2} \mathrm{O}(1: 1: 20)$ solution to release the structures. (g) After the seed layer was removed, thermal oxide was etched in BHF to expose the area to be recessed. (h) The silicon substrate was etched by $22.5 \mathrm{wt} \% \mathrm{KOH}$ at $70^{\circ} \mathrm{C}$ to create a $15 \mu \mathrm{m}$ recess.

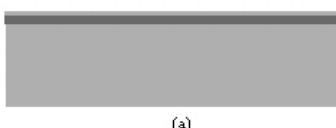

(a)

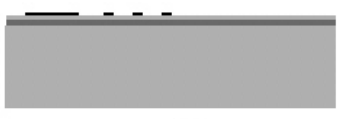

(b)

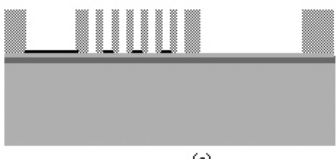

(c)

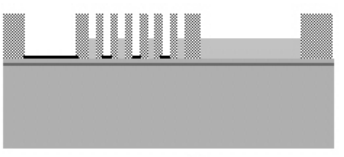

(d)

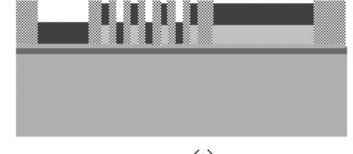

(e)
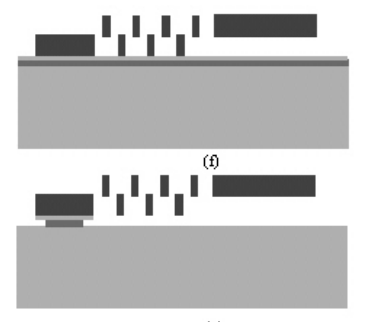

(g)

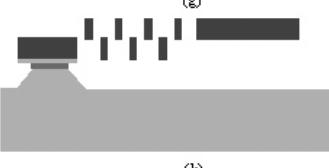

(h)
Figure 3. A typical process flow to fabricate mirrors with electroplated vertical comb drive actuators.

\section{RESULTS}

Fig.4 (a) and Fig.4 (b) show asymmetric comb fingers with different magnifications, where the length of comb fingers was $100 \mu \mathrm{m}$, while the designed width and spacing were $4 \mu \mathrm{m}$ and $6 \mu \mathrm{m}$, respectively. No significant buckling resulting from a residue stress gradient was observed on either the mirror or the comb fingers because of the thick structure and utilization of nickel sulfamate solution. However, some long beams $(300 \mu \mathrm{m})$ in the Type B mirror bent laterally with up to $5 \mu \mathrm{m}$ of deformation. The deformation was not observed before $\mathrm{KOH}$ etching. Therefore, the deformation was most likely caused by the air bubbles during $\mathrm{KOH}$ etching. This will be further investigated in the future. The results showed that the mirror with the designed geometry of $4 \mu \mathrm{m}$ comb finger width and $6 \mu \mathrm{m}$ comb finger spacing had higher yield and performance than one with $5 \mu \mathrm{m}$ comb finger width and $5 \mu \mathrm{m}$ spacing. In fact, the measured width of the comb fingers was about $5 \mu \mathrm{m}$ for the designed $4 \mu \mathrm{m}$ comb due to the lithography process. The mirror with the designed $6 \mu \mathrm{m}$ comb finger width and $6 \mu \mathrm{m}$ spacing had a bit higher yield than the same device with $4 \mu \mathrm{m}$ comb finger width and $6 \mu \mathrm{m}$ spacing, but the driving voltage was higher. The lower beams were about half micron narrower than the upper ones because of the profile of the photoresist mold. Before electroplating, the wafer was cut into pieces containing 4-6 dice. The deviation of thickness of photoresist mold was within $10 \%$.

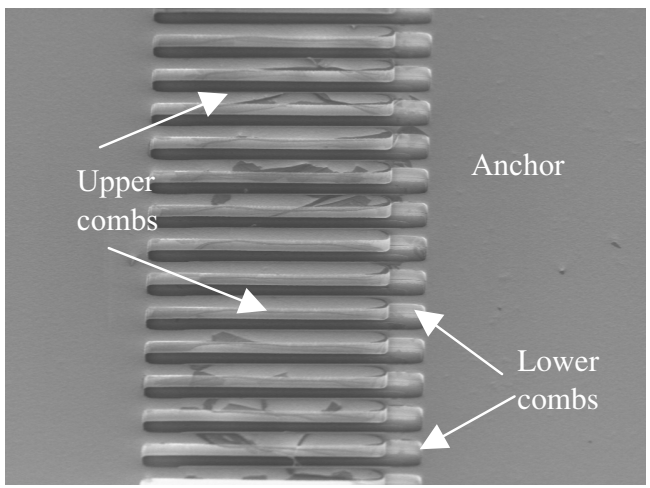

(a)

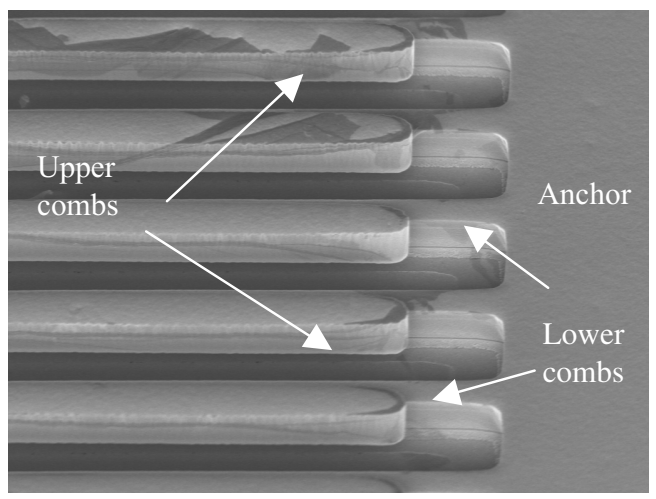

(b)

Figure 4. SEM micrographs of asymmetric comb fingers with different magnifications. The length of comb fingers was $100 \mu \mathrm{m}$, while the designed width and spacing were $4 \mu \mathrm{m}$ and $6 \mu \mathrm{m}$, respectively.

The mirrors were designed to operate at resonance, but they could also operate by being driven statically. The tilt angles under DC and AC actuation and frequency response were measured. In all of our measurements, the voltage was applied to a single side of the comb drives. 
Fig.5 shows the peak-to-peak tilt angle as a function of an applied square wave voltage with a $50 \%$ duty cycle at the resonant frequency. The maximum tilt angle was \pm 9.8 optical degrees at about $3.8 \mathrm{kHz}$ and $78 \mathrm{~V}$ for the Type B mirror with $100 \mu \mathrm{m}-$ long comb fingers. The Type A mirror with $100 \mu \mathrm{m}$-long and $5 \mu \mathrm{m}$-wide comb fingers had the maximum tilt angle of \pm 5 optical degree at about $4.6 \mathrm{kHz}$ and $65 \mathrm{~V}$. The mirror with $200-\mu \mathrm{m}$-long comb fingers had lower driving voltage, but the maximum tilt angle was much smaller.

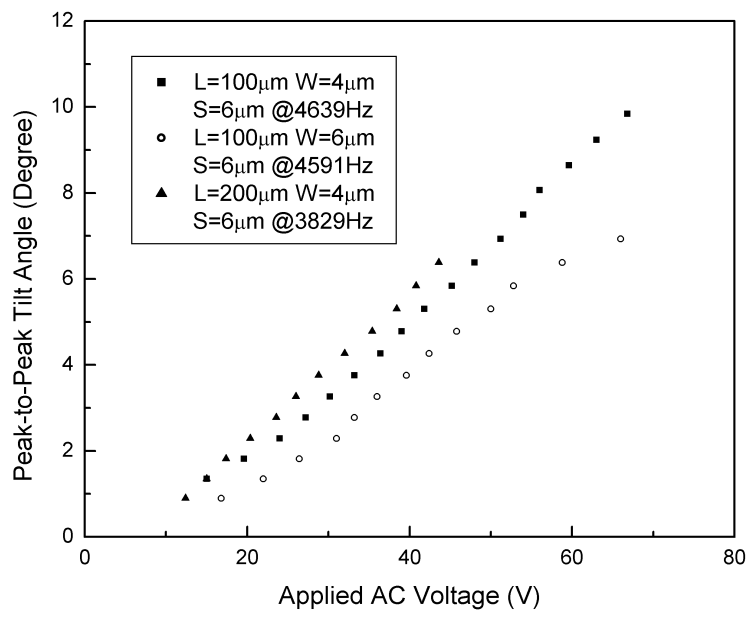

(a)

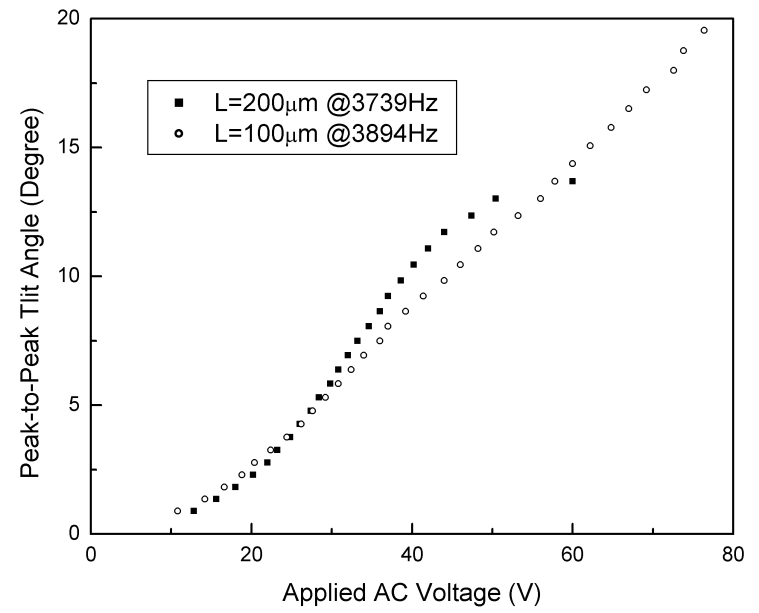

(b)

Figure 5. The peak-to-peak tilt angles as a function of the applied pulsed DC voltage at $50 \%$ duty cycle at the resonant frequency for (a) the Type A mirror and (b) the Type B mirror, where $L, W$ and $S$ are the designed length, width and spacing of the comb fingers. In the Type B mirror, the width and spacing of comb fingers are $4 \mu \mathrm{m}$ and $6 \mu \mathrm{m}$.

Fig.6 presents the frequency response of the mirrors. The resonant frequency of the Type A mirrors with the designed comb finger length of $100 \mu \mathrm{m}$ was about $4.6 \mathrm{kHz}$, with no significant difference for different comb widths, while the frequency of the mirrors with designed comb finger length of $200 \mu \mathrm{m}$ was about $3.8 \mathrm{kHz}$. The resonant frequencies of the Type B mirrors with comb finger length of $100 \mu \mathrm{m}$ and $200 \mu \mathrm{m}$ were $3.7 \mathrm{kHz}$ and $3.9 \mathrm{kHz}$, respectively.

Fig.7 shows the DC voltage dependence of tilt angles. The Type A mirror with the designed comb finger length of $100 \mu \mathrm{m}$, width of $4 \mu \mathrm{m}$ and spacing of $6 \mu \mathrm{m}$ reached the maximum tilt angle of 2.8 optical degree at $141 \mathrm{~V}$, after which the mirror was balanced. The angle coincided with the calculated value of 2.7 optical degrees, at the maximum capacitance position. The Type B mirror with $200 \mu \mathrm{m}$-long comb fingers and $100 \mu \mathrm{m}$-long comb fingers reached the maximum tilt angle of 2.5 optical degrees at $130 \mathrm{~V}$, and 2.4 optical degrees at $200 \mathrm{~V}$, respectively. The values were smaller than the calculated angle of 3.7 optical degrees. The reason was that the displacements other than rotation (normal translation or lateral translation) occurred when a DC voltage was applied to a single side of the comb fingers, because the design of torsional beams was not optimized.

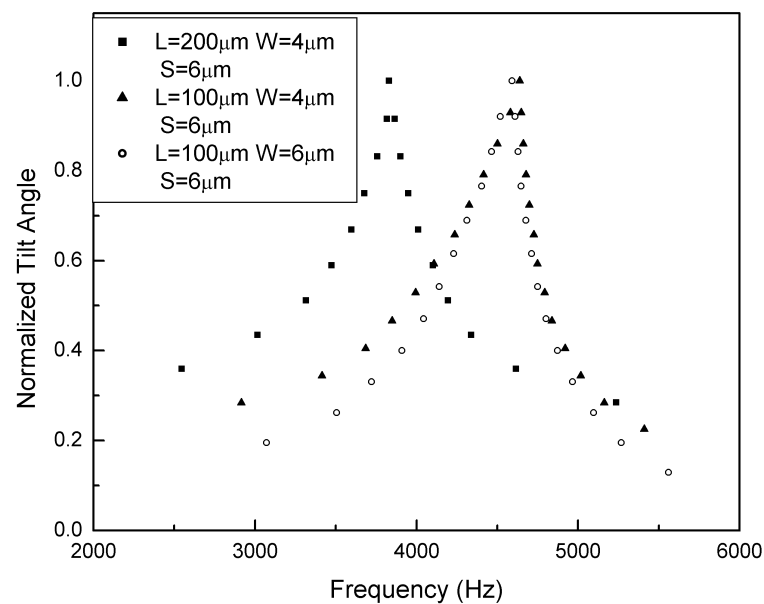

(a)

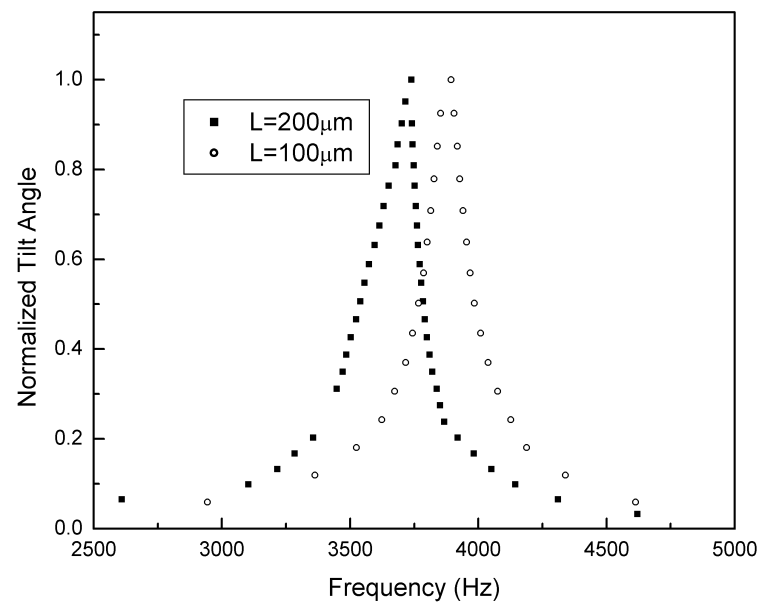

(b)

Figure 6. The frequency response for (a) the Type A mirror and (b) the Type B mirror. The tilt angle is normalized by the maximum tilt angle for each device. 


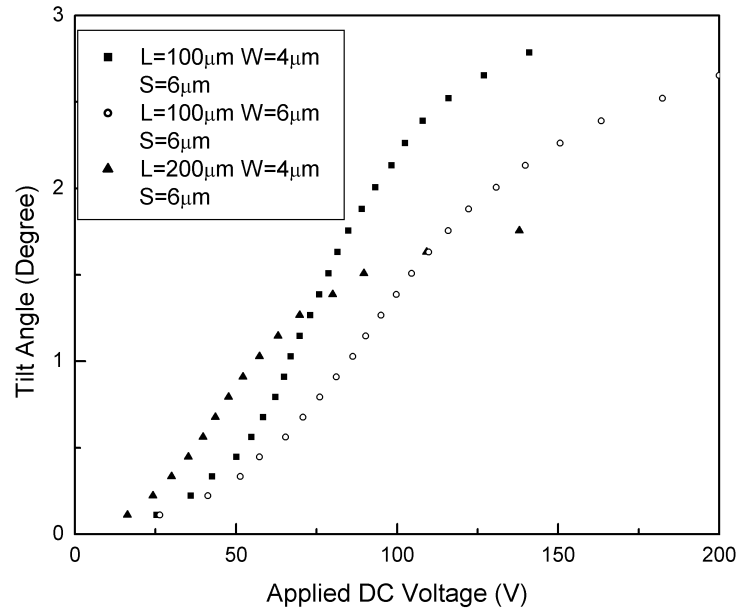

(a)

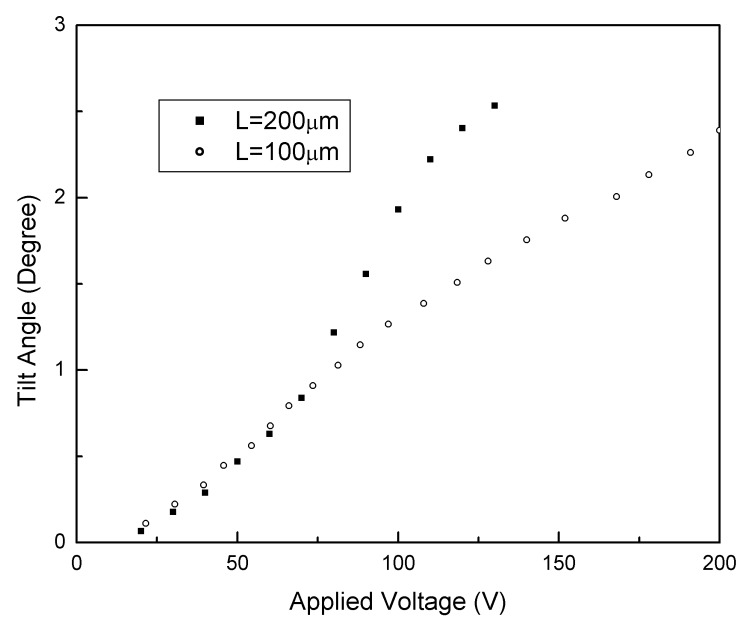

(b)

Figure 7. The DC voltage dependence of tilt angles for (a) the Type A mirror and (b) the Type B mirror

\section{CONCLUSIONS}

Utilizing a thick photoresist and electroplating process, a lowcost, vertical comb-drive actuator has been developed. In the process, a buried PECVD oxide mask and a $\mathrm{Cu}$ layer as a sacrificial and lifting layer allows $\mathrm{Ni}$ vertical asymmetric comb drives to be fabricated with self-alignment. Using this technique, two types of scanning mirrors with a reflecting area of $500 \mu \mathrm{m} \times 500 \mu \mathrm{m}$ have been designed, fabricated, and tested. The maximum tilt angle was \pm 9.8 optical degrees at about $3.8 \mathrm{kHz}$ and $78 \mathrm{~V}$ for the Type B mirror with $100 \mu \mathrm{m}$-long comb fingers, while the Type A mirror with the designed comb length of $100 \mu \mathrm{m}$, width of $4 \mu \mathrm{m}$ and spacing of $6 \mu \mathrm{m}$ reached the maximum tilt angle of 2.8 optical degree at $141 \mathrm{~V}$ DC voltage.

The evaluation of additional design parameters such as surface roughness, curvature, and reflectivity, and the application of the vertical comb-drive for tunable capacitors are in progress.

\section{AKNOWLEDGEMENT}

The authors would like to thank Dr. Daniel T. McCormick for his help in measurement and Mr. Qingquan Liu for Ni plating process.

\section{REFERENCES}

1. Y. Mizuno, O. Tsuboi, N. Kouma, H. Soneda, H. Okuda, Y. Nakamura, S. Ueda, I. Sawaki, and F. Yamagishi, "A 2-Axis Comb-Driven Micromirror Array for 3D MEMS Switches", Conference Digest of 2002 IEEE/LEOS International Conference on Optical MEMS, 8/20-23/02, Lugano, Switzerland (2002), pp. 17-18

2. V. Milanovic, S. Kwon, and L. P. Lee, "Monolithic Vertical Combdrive Actuators for Adaptive Optics", Conference Digest of 2002 IEEE/LEOS International Conference on Optical MEMS, 8/20-23/02, Lugano, Switzerland (2002), pp. 57-58

3. D. Hah, S. Huang, H. Nguyen, H. Chang, J. -C. Tsai, M. C. Wu, “Low Voltage MEMS Analog Micromirror Arrays with Hidden Vertical Comb-Drive Actuators", Technical Digest of the 1994 Solid-State Sensor and Actuator Workshop, Hilton Head Isl., SC, 6/13-16/94, Transducer Research Foundation, Cleveland (1994), pp. 11-14

4. D. McCormick, Ph. D. Dissertation, Cornell University, 2003

5. J. A. Yeh, H. Jiang, and N. C. Tien, "Integrated Polysilicon and DRIE Bulk Silicon Micromachining for an Electrostatic Torsional Actuator", Journal of Microelectromechanical Systems, 8, 4(1999), pp.456-465

6. H. Nguyen, D. Hah, P. R. Patterson, W. Piywattanametha, M. C. Wu, "A Novel MEMS Tunable Capacitor Based on Angular Vertical Comb Drive Actuators”, Technical Digest of the 1994 Solid-State Sensor and Actuator Workshop, Hilton Head Isl., SC, 6/13-16/94, Transducer Research Foundation, Cleveland (1994), pp. 277-279

7. X. Li, S. Kiyawat, and C.-J. Kim, "High-Aspect-Ratio Electroplated Structures with $2 \mu \mathrm{m}$ Beamwidth, Proc. MEMS (MEMS-Vol. 1), ASME Int. Mechanical Engineering Congress and Exposition, Nashville, TN, (1999), pp. 25-30.

8. J. Quemper, S. Nicolas, J. P. Grandchamp, A. Bosseboeuf, T. Bourouina, and E. Dufour-Gergam, "Permalloy Electroplating through Photoresist Molds", Sensors and Actuators, 74 (1999), pp. 1-4

9. H. Lorenz, M. Despont, N. Fahrni, N. Labianca, P. Renaud and V. Vettiger, "SU-8: a Low-cost Negative Resist for MEMS", J. Micromech. Microeng, 7(1997), pp. 121-124

10. E. H. Conradie and D. F. Moore, "SU-8 Thick Photoresist Processinf as a Functional Material for MEMS Applications", J. Micromech. Microeng, 12(2002), pp. 368-374 